Dhaka Univ. J. Biol. Sci. 23(1): 69-76, 2014 (January)

\title{
RELATION OF PARENTAL REJECTION WITH SELF-ESTEEM AND LIFE SATISFACTION OF YOUNG ADULTS
}

\author{
SHAmima Yasmin AND Afroza Hossain \\ Department of Psychology, University of Dhaka, Dhaka-1000, Bangladesh
}

Key words: Relation, Parental rejection, Self-esteem, Young adults

\begin{abstract}
The present study was designed to study the relation of parental rejection with self-esteem and life satisfaction. A total of 30 males and 30 females were selected purposively from Dhaka city. Correlation analysis indicated that paternal- and maternal rejection had significant negative correlation with selfesteem and life satisfaction. Adjusted $\mathrm{R}^{2}$ of regression analysis indicated that parental rejection was the most important predictor which explained $70.4 \%$ of self-esteem and $25.6 \%$ variance of life satisfaction. Parental rejection greatly influence in offspring's self-esteem and life satisfaction. Self-esteem is more influenced by parental rejection than life satisfaction.
\end{abstract}

\section{Introduction}

Parental acceptance rejection (PAR) theory predicts that parental rejection has consistent negative effects on the psychological adjustment and on behavioral functioning of both children and adults worldwide. Parental acceptance-rejection sometimes has significantly greater impact than maternal acceptance-rejection on offspring's psychological adjustment ${ }^{(1-2)}$. Maternal and especially paternal acceptance always make significant contributions to offspring's psychological adjustment, even after controlling for a variety of psychological as well as demographic factors ${ }^{(2-4)}$.

Emotional support from parents positively relates to identity achievement during adolescence investigated the relationship between parental unconditional positive regard and adult self-esteem and found higher parental unconditional positive regard was related to higher self-esteem in both adult men and women ${ }^{(5-6)}$. Low care, overprotective parenting style has been found to be harmful to children's self-esteem ${ }^{(7-8)}$ and low selfesteem negatively impacts one's psychological well-being and overall life satisfaction ${ }^{(9-10)}$. Amato found that emotional closeness to parents significantly predicted offspring happiness and life satisfaction with both mother and father making unique contributions to offspring happiness and life satisfaction ${ }^{(11)}$.

Self-esteem is a term in psychology to reflect a person's overall evaluation or appraisal of his or her own worth ${ }^{(12,13)}$. Parenting, and in particular parental involvement and closeness to parents have been investigated as predictors of later psychological outcomes which are likely to determine life satisfaction ${ }^{(14,15)}$. 
A lack of parental emotional support is associated with increased levels of depressive symptoms and chronic health problem in adulthood. Sato found that individuals who view their parents as overprotective and less caring, and tended to have depressive disorders as adults(16).

Western individualistic societies have identified many factors with parental rejection as the strongest predictors. In Bangladesh there is so far no deal with the possible relationship between paternal rejection and offspring's self esteem and life satisfaction, even though they are future contributors to the nation. According to above reviews and objectives it was hypothesized that parental rejection will be negatively correlated with self-esteem and life satisfaction. The aim of the present study is to investigate the relation of parental rejection with self-esteem and life satisfaction.

\section{Materials and Methods}

A total of 60 young adults were taken from different area of Dhaka city by purposive with non probability sampling technique. Among them 30 were males and 30 were females. The age of the respondents was between 20 and 40 years. Their educational qualification ranged from class twelve to post graduation. Purposive sample has been taken to collect data with convenient time and financial involvement.

To measure the parental acceptance and rejection, the father and mother versions of the PARQ/control are originally developed by Rohner(17-18), and adapted in Bangla by Jasmine et al.(19) is used. Self-esteem is measured by Ilyas's (Personnel communition) Bangla version of Rosenberg self-esteem scale. Ilyas's Bangla version of Rosenberg's Selfesteem scale ${ }^{(12)}$ was originally developed to measure adolescent's feeling of self-worth or self-acceptance. Adapted Bangla version by Ilyas ${ }^{(10)}$, Diener's satisfaction with life scale (SWLS) ${ }^{(10)}$ was used for measuring life satisfaction.

The above instruments were administered individually to the members of the sample. They were informed of the purpose of the present study and necessary rapport was established before administering the questionnaires. Individual setting was made during administering questionnaire. Respondents were instructed to read the items of the scales attentively and to respond carefully. All necessary clarifications were made regarding the items. They were asked to give tick $(\sqrt{ })$ mark in the appropriate box. They were also requested not to omit any item in the questionnaire and told that there was no right and wrong answer and no time limit for answering. All the data were collected within one month.

\section{Results and Discussion}

It was hypothesized that parental rejection would be negatively correlated with selfesteem and life satisfaction. To investigate the relation of parental rejection of variables correlation and multiple regression analysis were used. 
The inter correlations of the subscales and total PARQ; Mother, self-esteem and life satisfaction indicated that mother's reverse warmth/affection has significant negative correlation with self-esteem $\left(\mathrm{r}=-0.322,{ }^{*} \mathrm{p}<0.05\right)$ but no significant correlation with life satisfaction $(\mathrm{r}=-0.025)$, Hostility/aggression has significant negative correlation with self esteem $\left(r=-0.417,{ }^{*} p<0.05\right)$, and negative but no significant correlation with life satisfaction $(r=0.055)$, Indifference/neglect has significant negative correlation with self esteem $\left(r=-0.300,{ }^{*} p<0.05\right)$, and negative but not significantly correlated with life satisfaction $(\mathrm{r}=-0.109)$, Undifferentiated/rejection has negative correlation with self esteem $(r=-0.172)$ and life satisfaction $(r=-0.098)$, Total mother PARQ score has significant negative correlation with self esteem $\left(\mathrm{r}=-0.717,{ }^{* *} \mathrm{p}<0.01\right)$ and life satisfaction $\left(\mathrm{r}=-0.515,{ }^{* *} \mathrm{p}<0.01\right)$ and self esteem has significant positive correlation with life satisfaction $\left(\mathrm{r}=0.503,{ }^{* *} \mathrm{p}<0.01\right)$. The results of correlation showed that a person with higher scores in the scale measuring maternal rejection (PARQ: Mother) had lower scores in self-esteem and life satisfaction scale.

The inter correlations of the subscales and total PARQ; Father, self-esteem and life satisfaction indicated that father's reverse warmth/affection has significant negative correlation with self esteem $\left(r=-0.315,{ }^{*} p<0.05\right)$ and negative but no significant correlation with life satisfaction $(\mathrm{r}=-0.125)$, hostility/aggression has significant negative correlation with self esteem $\left(\mathrm{r}=-0.316,{ }^{*} \mathrm{p}<0.05\right)$, and negative but not significantly correlated with life satisfaction $(r=-0.052)$, indifference/ neglect has significant negative correlation with self esteem $\left(\mathrm{r}=-0.295,{ }^{*} \mathrm{p}<0.01\right)$, and negative but no significant correlation with life satisfaction $(\mathrm{r}=-0.095)$, undifferentiated/rejection has negative correlation with self esteem $(r=-0.156)$ and negative correlation with life satisfaction $(r=$ - 0.211), total father PARQ score has significant negative correlation with self-esteem $(r=$ - 0.775, $\left.{ }^{* *} \mathrm{p}<0.01\right)$ and life satisfaction $\left(\mathrm{r}=-0.438,{ }^{* *} \mathrm{p}<0.01\right)$ and self-esteem has significant positive correlation with life satisfaction $\left(\mathrm{r}=0.503,{ }^{* *} \mathrm{p}<0.01\right)$. The results of correlation showed that, a person with higher scores in the scale measuring paternal rejection (PARQ : Mother) had higher scores in self-esteem and life satisfaction scale.

Thus results of this research confirmed the hypotheses. This result also showed that self-esteem is positively correlated with life satisfaction $\left(\mathrm{r}=0.503,{ }^{* *} \mathrm{p}<0.01\right)$. The result supports previous study. Forsman ${ }^{(6)}$ investigated the relationship between parental unconditional positive regard and adult self-esteem and found higher parental unconditional positive regard was related to higher self-esteem in both adult men and women. Amato(11) found that emotional closeness to parents significantly predicted offspring happiness and life satisfaction with both mother and father making unique contributions to offspring happiness and life satisfaction. So, it is stated that, in Bangladesh context, the young adults who viewed their parents as rejecting reported low self-esteem and low satisfaction in life. Correlation among self-esteem and subscales of 
PARQ : Mother (Reverse warmth/affection, hostility/aggression, indifference/neglect) is significant.

Regression analysis of self-esteem on sub scales of PARQ: Mother is shown in Table 1. The value of adjusted $R^{2}$ (adjusted $R^{2}=0.172, F_{3,56}=5.079, p<0.01$ ) of Table 1 indicated that the model explained $17.2 \%$ of the variance in self-esteem. Standardized beta coefficients $(\beta)$ in Table 1 indicated that 1 unit increase in maternal reverse warmth/affection decreases 0.180 unit in self-esteem $(\beta=-0.180), 1$ unit increase in maternal hostility/aggression decreases 0.302 unit in self-esteem $(\beta=-0.302)$ and 1 unit increase in maternal indifference/neglect decreases 0.067 unit in self-esteem $\quad(\beta=-0.067)$. Furthermore, the value of part correlation indicated that the unique contribution to the explanation of variance in self-esteem was highest for mother's hostility/aggression $(8.47 \%)$ followed by reverse warmth/affection $(3.84 \%)$ and indifference/neglect $(0.22 \%)$. The result showed that, mother's hostility/aggression was more influential for offspring's self-esteem.

Table 1. Regression analysis of self-esteem on sub scales of PARQ : Mother.

\begin{tabular}{|c|c|c|c|c|c|c|c|}
\hline \multirow{3}{*}{$\begin{array}{l}\text { Predictor } \\
\text { variables }\end{array}$} & \multicolumn{3}{|c|}{ Unstandardized Standardized } & \multirow{3}{*}{$\mathrm{t}$} & \multirow{3}{*}{$\mathrm{p}$} & \multirow{3}{*}{$\mathrm{r}_{p}$} & \multirow{3}{*}{$\begin{array}{c}\text { Unique } \\
\text { contribution } \\
\mathrm{r}^{2} p \times 100\end{array}$} \\
\hline & coeffic & ent & coefficient & & & & \\
\hline & $\mathrm{B}$ & SE & $\beta$ & & & & \\
\hline Constant & 46.788 & 4.686 & & 9.985 & 0.001 & & \\
\hline \multicolumn{8}{|l|}{ PARQ : Mother } \\
\hline Reverse warmth/ affection & -0.180 & 0.108 & -0.227 & -1.658 & 0.103 & -0.196 & 3.84 \\
\hline Hostility/aggression & -0.302 & 0.123 & -0.381 & -2.457 & 0.017 & -0.291 & 8.47 \\
\hline Indifference/neglect & -0.067 & 0.190 & -0.060 & -0.354 & 0.724 & -0.047 & 0.22 \\
\hline
\end{tabular}

Adjusted $\mathrm{R}^{2}=0.172, \mathrm{~F} 3,56=5.079, \mathrm{p}<0.01$.

Table 2 is delineating the regression analysis of self-esteem on sub scales of PARQ: Father. The value of adjusted $\mathrm{R}^{2}$ (adjusted $\mathrm{R}^{2}=0.100, \mathrm{~F} 3,56=3.175, \mathrm{p}<0.01$ ) of Table 2 indicated that the model explained $10 \%$ of the variance in self-esteem. Standardized beta coefficients $(\beta)$ in Table 2 indicated that 1 unit increase in father's reverse warmth/affection decreases 0.183 unit in self-esteem $(\beta=-0.183), 1$ unit increase in father's hostility/aggression decreases 0.141 unit in self-esteem $\quad(\beta=-0.141), 1$ unit increase in father's indifference/neglect decreases 0.071 unit in self-esteem. Furthermore, the value of part correlation indicated that the unique contribution to the explanation of variance in self-esteem was highest for father's reverse warmth/affection $(3.49 \%)$ followed by hostility/aggression $(1.79 \%)$ and indifference/neglect $(0.17 \%)$. The result showed that father's reverse warmth/affection had greater impact on self-esteem.

This result also showed that maternal rejection can explain $17.2 \%$ variance of selfesteem (Table 1) and paternal rejection can explain 10\% variance of self-esteem (Table 2). It is revealed from the result that maternal rejection is more influential for the variation in 
self-esteem. Maternal rejection has a significantly greater impact on life satisfaction than paternal rejection. This result also showed that parental rejection can explain $70.4 \%$ variance of self-esteem and $25.6 \%$ variance of life satisfaction. This result suggests that, self-esteem is more influenced by parental rejection than life satisfaction. This result support previous study. Research conducted in Western societies had reported that warm loving and caring parenting practices in childhood helped to faster the development of healthy self-esteem in children and therefore increased their psychological well-being as young adults(21). Previous research has shown that individuals who perceived parents as punitive, rejecting, and controlling reported lower ratings of life satisfaction than those with a more positive experience with parents(22-24). Parental acceptance is necessary for the development of a positive self concept ${ }^{(25)}$. So, we can conclude that, in the context of our country parent's warmth and affection is necessary for the development of both high self-esteem and life satisfaction. Between these two parental love is more necessary for self-esteem and life satisfaction may be influenced by other factors that should be identified by further research.

Table 2. Regression analysis of self-esteem on sub scales of PARQ : Father.

\begin{tabular}{|c|c|c|c|c|c|c|c|}
\hline \multirow[t]{2}{*}{$\begin{array}{l}\text { Predictor } \\
\text { variables }\end{array}$} & \multicolumn{3}{|c|}{ Unstandardized Standardized } & \multirow[t]{2}{*}{$\mathrm{t}$} & \multirow[t]{2}{*}{$\mathrm{p}$} & \multirow[t]{2}{*}{$\mathbf{r}_{p}$} & \multirow{2}{*}{$\begin{array}{c}\text { Unique } \\
\text { contribution } \\
\mathrm{r}_{p}^{2} \times 100\end{array}$} \\
\hline & B & SE & $\beta$ & & & & \\
\hline Constant & 46.097 & 5.37 & & 8.585 & 0.001 & & \\
\hline \multicolumn{8}{|l|}{ PARQ : Father } \\
\hline Reverse warmth/affection & -0.183 & 0.121 & -0.213 & -1.515 & 0.135 & -0.187 & 3.49 \\
\hline Hostility/aggression & -0.141 & 0.130 & -0.190 & -1.085 & 0.238 & -0.134 & 1.79 \\
\hline Indifference/neglect & -0.071 & 0.211 & -0.062 & -0.338 & 0.737 & -0.042 & 0.17 \\
\hline
\end{tabular}

Adjusted $\mathrm{R}^{2}=0.100, \mathrm{~F} 3,56=3.175, \mathrm{p}<0.01$.

Regression analysis of self-esteem on PARQ : Father and PARQ : Mother is shown in Table 3. The value of adjusted $R^{2}$ (adjusted $R^{2}=0.704, F 2,57=71.215, p<0.01$ ) Table 3 indicated that the model explained $70.4 \%$ of the variance in self-esteem.

Table 3. Regression analysis of self esteem on PARQ : Father and PARQ : Mother.

\begin{tabular}{lccccccc}
\hline $\begin{array}{l}\text { Predictor } \\
\text { variables }\end{array}$ & \multicolumn{2}{c}{$\begin{array}{c}\text { Unstandardized } \\
\text { coefficient }\end{array}$} & $\begin{array}{c}\text { Standardized } \\
\text { coefficient }\end{array}$ & $\mathrm{t}$ & $\mathrm{p}$ & $\mathrm{r}_{p}$ & $\begin{array}{c}\text { Unique } \\
\text { contribution } \\
\mathrm{r}^{2} \times 100\end{array}$ \\
\cline { 2 - 5 } & $\mathrm{B}$ & $\mathrm{SE}$ & $\beta$ & & & & \\
\hline Constant & 64.072 & 2.808 & & 22.819 & 0.001 & & \\
PARQ : Father & -0.131 & 0.027 & -0.468 & -4.890 & 0.001 & -0.346 & 11.97 \\
PARQ : Mother & -0.141 & 0.030 & -0.485 & -4.769 & 0.001 & -0.388 & 15.05 \\
\hline
\end{tabular}

Adjusted $\mathrm{R}^{2}=0.704, \mathrm{~F} 2,57=71.215, \mathrm{p}<0.01$.

Standardized beta coefficients $(\beta)$ in Table 3 indicated that 1 unit increase in paternal rejection decreases 0.468 unit in self-esteem $(\beta=-0.468)$ and 1 unit increase in maternal 
rejection decreases 0.485 unit in self-esteem $(\beta=-0.485)$. So, paternal and maternal rejection both were strong predictor of self-esteem. Furthermore, the value of part correlation indicated that the unique contribution to the explanation of variance in selfesteem was highest for Mother : PARQ (15.05\%) followed by father : PARQ (11.97\%).

Multiple regression of life satisfaction on PARQ : Father and PARQ : Mother is shown in Table 4 . The value of adjusted $\mathrm{R}^{2}$ (adjusted $\mathrm{R}^{2}=0.256, \mathrm{~F} 2,57=11.124, \mathrm{p}<0.01$ ) of Table 4 indicated that the model explained $25.6 \%$ of the variance in life satisfaction. Standardized beta coefficients $(\beta)$ in Table 4 indicated that 1 unit increase in paternal rejection decreases 0.167 unit in life satisfaction $(\beta=-0.167)$ and 1 unit increase in maternal rejection decreases 0.403 unit in life satisfaction $(\beta=-0.403)$. Furthermore, the value of part correlation indicates that the unique contribution to the explanation of variance in life satisfaction was highest for mother: PARQ $(8.88 \%)$ followed by father: PARQ (1.53\%). The result showed that, maternal rejection was the strongest predictor of life satisfaction between maternal and paternal rejection.

Table 4. Multiple regression of life satisfaction on PARQ : Father and PARQ : Mother.

\begin{tabular}{lccccccc}
\hline \multirow{2}{*}{$\begin{array}{l}\text { Predictor } \\
\text { variables }\end{array}$} & \multicolumn{2}{c}{$\begin{array}{c}\text { Unstandardized } \\
\text { coefficient }\end{array}$} & $\begin{array}{c}\text { Standardized } \\
\text { coefficient }\end{array}$ & $\mathrm{t}$ & $\mathrm{p}$ & $\mathrm{r}_{p}$ & $\begin{array}{c}\text { Unique } \\
\text { contribution } \\
\mathrm{r}^{2} p \times 100\end{array}$ \\
\cline { 2 - 4 } Constant & $\mathrm{B}$ & $\mathrm{SE}$ & $\beta$ & & 10.825 & 0.001 & \\
PARQ : Father & -0.042 & 0.038 & -0.167 & -1.101 & 0.275 & -0.124 & 1.53 \\
PARQ : Mother & -0.111 & 0.042 & -0.403 & -2.654 & 0.010 & -0.298 & 8.88 \\
\hline
\end{tabular}

Adjusted $\mathrm{R}^{2}=0.256, \mathrm{~F} 2,57=11.124, \mathrm{p}<0.01$.

The unique contribution of maternal rejection in variance of self-esteem was $15.05 \%$ and it was $11.97 \%$ for paternal rejection (Table 3). The unique contribution of maternal rejection in variance of life satisfaction was $8.88 \%$ where it was $1.53 \%$ for paternal rejection (Table 4). So, the result suggests that maternal and paternal rejection both are strong predictor of self-esteem and maternal rejection is the strongest predictor of life satisfaction.

The hypothesis that parental rejection would be associated with low level of selfesteem and low level of life satisfaction was verified in this study. Consistent with the expectations, parental rejection was found to be negatively associated with self-esteem and life satisfaction scores. This result also suggests that maternal rejection has greater impact on self-esteem and life satisfaction than paternal rejection. The close affection bond with mothers and their children develop higher self-esteem and higher life satisfaction in their children. Mother involvement at age 7 was more significantly related to self-esteem and life satisfaction. It is speculated that the close affection bond between mothers and their children forms the core of Bangladeshi family relationship. In Bangladeshi child rearing mothers generally spend more time with children than do 
fathers. For this reason, children may become less attentive to fathers' behavior than do mothers'. So it may be natural that, mothers, rejected behaviors sometimes have greater impact on offspring's self esteem and life satisfaction. Although maternal rejection has greater impact on self esteem and life satisfaction, the result shows that, paternal rejection has also significant impact on self-esteem and life satisfaction. Both maternal and paternal involvement in childhood is important to develop offspring's high selfesteem and life satisfaction in adulthood.

In conclusion, professionals seeking to improve the general psychological well-being of young adults may use the results of this study to consider evidence-based interventions aimed at increasing self-esteem and life satisfaction.

\section{References}

1. Rohner RP 1998. Father love and child development: History and current evidence. Current Directions in Psychological Science 7: 157-161.

2. Rohner RP and RA Veneziano 2001. The importance of father love: History and contemporary evidence. Review of General Psychology 15: 25-44.

3. Khaleque A and RP Rohner 2002a. Perceived parental acceptance-rejection and psychological adjustment: A meta-analysis of cross cultural and intercultural studies. Journal of Marriage and the Family 64: 54-64.

4. Rohner RP and PA Britner 2002. Worldwide mental health correlates of parental acceptancerejection: Review of cross-cultural and intracultural evidence. Cross-Cultural Research. 36: 16-47.

5. Sartor CE and J Youniss 2002. The relationship between positive parental involvement and identity achievement during adolescence. Adolescence. Summer 37(146): 221-234.

6. Forsman L 1989. Parent-child gender interaction in the relation between retrospective selfreports on parental love and current self-esteem. Scandinavian Journal of Psychology 30: 275-283.

7. Harvey M and M Byrd 1998. The relationship between perceptions of self esteem, patterns of family attachment \& family environment during early \& late phases of adolescence. Int. J. Adolesc. Youth 7: 93-111.

8. Mori M 1999. The influence of father-daughter relationship and girls' sex-role on girls selfesteem. Archiv. Women Mental Health 2: 45-47.

9. Abe J 2004. Self-esteem, perception of relationships and emotional distress: A cross-cultural study. Pers. Relat. 11: 231-247.

10. Diener E, RA Emmors, RJ Larsen and S Griffin 1985. The satisfaction with life scale. Journal of Personality Assessment. 49(1): 71-75.

11. Amato PR 1994. 'Father-child relations, mother-child relations, and offspring psychological well-being in early adulthood'. J. Marriage and the Family 56: 1031-1042.

12. Rosenberg M 1965. Society and the adolescent self-image, Princeton NJ (ed.), Princeton University Press.

13. Branden N 1969. The Psychology of self-esteem. New York, Bantam. 
14. Flouri E and A Buchanan 2002b. What predicts good relationships with parents in adolescence and parents in adult life: Findings from the 1958 British birth cohort. J. Family Psychol. 16: 186-198.

15. Ryan RM and EL Deci 2001. To be happy or to be self-fulfilled: A review of research on hedonic and eudaimonic well-being. In: Annual Review of Psychology, Fiske S (Ed.), 52: 141166. Palo Atto, (A. Annual Reviews/Inc.)

16. Sato T, K Sakado, T Uehara, K Nishioka and Y Kashahara 1997. Perceived parental styles in a Japanese sample of depressive disorders : A replication outside western culture. Br. J. Psychiatr. 170:173-175.

17. Rohner RP 2005. Parental acceptance-rejection/control questionnaire (PARQ/Control). Test manual. In: Handbook for the study of parental acceptance and rejection (4 ${ }^{\text {th }}$ edition), RP Rohner and A Khaleque (Eds.), pp. 137-186). Storrs, CT : Rohner Research Publications.

18. Rohner RP 1990. Handbook for the study of parental acceptance and rejection (3 ${ }^{\text {rd }}$ ed.) Storrs, CT: Rohner Research Publications.

19. Jasmine UH, MK Uddin and S Sultana 2007. Adaptation of the parental acceptance- rejection questionnaire and personality assessment questionnaire in Bangla language. Bangladesh Psychological Studies 17: 49-70.

20. Ilyas QSM 2002. Bangla version of Diener's et al., Satisfaction with life scale (SWLS). Department of Psychology. University of Dhaka.

21. Restifo K and SM Bögels 2009. Family risk factors for youth depression: A family systems integration and treatment model. Clinical Psychotherapy. 29: 357-374.

22. Lamborn SD, NS Mounts, L Steinberg, and SM Dornbusch 1991. Patterns of competence \& adjustment among adolescents from authoritative, authoritarian, indulgent and neglectful families. Child Dev. 62: 1049-1065.

23. Petrowski K, H Berth, S Schmidt, J Schumacher, Hinza and E Brahler 2009. The assessment of recalled parental rearing behavior and its relationship of life satisfaction and interpersonal problems: A general population study. BMC. Med. Res. Methodol. 9: 17.

24. Winefield HR, RD Goldney, M Tiggemann and AH Winefield 1989. Reported parental rearing patterns and psychological adjustment: A short form of the EMBU. Personality and Individual differences 10(4): 459-465.

25. Rosenthal R 1973. Non-verbal communication and the self fulfilling prophecy. Independent Education 3: 6-9. 